\title{
Dietary Intake in a Randomized-Controlled Pilot of NOURISH: A Parent Intervention for Overweight Children
}

\author{
Melanie K. Bean, $\mathrm{PhD}^{\mathrm{a}, \mathrm{b}}$, Diane Baer Wilson, EdD, RD ${ }^{\mathrm{c}, \mathrm{d}}$, Laura M. Thornton, $\mathrm{PhD}^{\mathrm{e}}$, Nichole \\ Kelly, MS ${ }^{b}$, and Suzanne E. Mazzeo, PhD $^{\mathrm{b}, a}$ \\ aDepartment of Pediatrics, Children's Hospital of Richmond at Virginia Commonwealth University, \\ PO Box 980140, Richmond, VA, 23298-0140, USA \\ bDepartment of Psychology, Virginia Commonwealth University, PO Box 842018, Richmond, VA, \\ 23284-2018, USA \\ c,dDepartment of Internal Medicine and the Massey Cancer Center, PO Box 980306, Richmond, \\ VA, 23298-0306, USA \\ eDepartment of Psychiatry, University of North Carolina at Chapel Hill, 101 Manning Road, CB \\ \#7160, Chapel Hill, NC, 27599-7160 USA
}

\begin{abstract}
Objective-NOURISH is a community-based treatment program for parents of overweight and obese children (ages $6-11$, BMI $\geq 85$ th percentile). This study examined the impact of NOURISH on child and parent dietary intake, secondary trial outcomes.
\end{abstract}

\begin{abstract}
Methods-In Virginia from 2008-2009, this randomized controlled pilot was implemented and dietary assessment of parents and children conducted at baseline, post-test, and 6-month followup. Parents ( $85 \%$ female, $62 \%$ African American, mean BMI=34.1 \pm 9.1$)$ were randomized into intervention $(n=46)$ or control $(n=50)$ groups. Children's (mean age $=8.6 \pm 1.5)$ mean BMI percentile was $98.1 \pm 2.6$. Parents completed 24-hour dietary records for themselves and their child(ren). Repeated measures analyses assessed treatment effects over time. T-tests evaluated within-group changes from baseline to post-test and to follow-up, using a modified intent-to-treat approach.
\end{abstract}

Results-Both groups reported significant dietary changes, with few treatment effects found. For parents in NOURISH, significant improvements were found in intakes of total kilocalories/day, grams/day of carbohydrates and sugar, and percent calories from protein $(p<0.05)$. Among control group children, significant improvements in total kilocalories/day and grams/day of carbohydrates and sugar were found $(p<0.05)$.

Conclusions-Among parents who self-select into a childhood obesity program, minimal intervention can elicit short-term dietary changes comparable to those of a structured intervention.

\footnotetext{
(c) 2012 Elsevier Inc. All rights reserved.

Corresponding Author: Suzanne E. Mazzeo, Department of Psychology, PO Box 842018, Virginia Commonwealth University, Richmond, VA 23284-2018, Tel: 804-827-1708, Fax: 804-828-2237, semazzeo@vcu.edu.

Publisher's Disclaimer: This is a PDF file of an unedited manuscript that has been accepted for publication. As a service to our customers we are providing this early version of the manuscript. The manuscript will undergo copyediting, typesetting, and review of the resulting proof before it is published in its final citable form. Please note that during the production process errors may be discovered which could affect the content, and all legal disclaimers that apply to the journal pertain.

Conflict of Interest Statement: The authors declare that there are no conflicts of interest to report.
} 


\section{Keywords}

parent; diet; pediatric obesity

\section{Introduction}

Over one-third of U.S. children are overweight or obese, with higher rates among African Americans (AAs; Ogden et al., 2012). Interventions are urgently needed to reduce the significant consequences of pediatric obesity, and prevent adult morbidity (Whitaker et al., 1997).

Parent involvement in pediatric obesity treatment results in improved weight outcomes (Collins et al., 2011; Kitzmann et al., 2010). Compared to family-based interventions, parent-only interventions yield greater reductions in childhood overweight and are more cost-effective (Golan et al., 2006; Janicke et al., 2009). However, previous studies of parentonly interventions targeted predominately White families, and may not generalize to AAs. Interventions that address the cultural and pragmatic needs of AA families are needed (Koplan et al., 2005). Towards that end, we developed and demonstrated the feasibility of NOURISH (Nourishing Our Understanding of Role-modeling to Increase Support and Health), a parent-only intervention for overweight children, culturally tailored to AA families (Mazzeo et al., 2008; Mazzeo et al., 2012).

Grounded in Social Cognitive Theory (Bandura, 1986), NOURISH provides intensive parent skills training, emphasizing role modeling of positive health behaviors to foster healthy eating and exercise in children. Despite the importance of diet in the development and maintenance of obesity, dietary intake is rarely reported in pediatric obesity interventions (Collins et al., 2006). We thus examined dietary changes, hypothesizing that NOURISH participants and their children would demonstrate greater improvements in dietary intake compared to controls.

\section{Methods}

From 2008-2009 in Virginia, a randomized controlled trial of NOURISH was implemented in five waves of $\sim 22$ participants each (see Mazzeo et al., 2012 for intervention details). NOURISH focused on parenting skills and role-modeling to improve family-based health behaviors. Specific strategies to enhance nutrition were integrated throughout the groupbased intervention, including those focused on label reading, reducing sugar-sweetened beverages and increasing fruit and vegetable intake, and portion control. In the control group, an independent interventionist moderated a single group session addressing the roles of diet and exercise in pediatric overweight. Control parents were mailed publicly available brochures on pediatric overweight on two occasions. Procedures were approved by the Institutional Review Board.

\section{Participants}

Parents living with their child ages 6-11 with a BMI $\geq 85$ th percentile (CDC, 2000) were eligible. Parents who were pregnant, non-English-speaking, unable to exercise or participate in a group were excluded, as were parents of children with an underlying medical etiology of obesity (e.g., Prader-Willi Syndrome). 


\section{Measures}

Assessments were completed at baseline, post-test (immediately following the intervention), and 6-month follow-up. Parents were mailed handouts to assist with their completion of 24hour food records for themselves and their child(ren) at each time point; handouts included information and pictures to help parents estimate portions. Parent-reported intake is more valid than self-report for young children, with demonstrated convergence with observational methods (Samet and Alberg, 1998). Trained interventionists interviewed families to review records, with prompts and food pictures, similar to a dietary recall. Nutrition Data System Software (Feskanich et al., 1989) analyzed dietary intake.

\section{Data Analyses}

Analyses were conducted using SAS version 9.2 (2004). Participants who indicated their ethnicity/race as something other than AA or White were excluded from analyses, as the number of families $(n=3)$ was too low for meaningful comparisons. Groups were compared on demographics at baseline using chi-square analyses and t-tests. Two-group repeated measures analyses of variance using PROC MIXED assessed group differences on dietary measures over time. Models adjusted for parent's ethnicity/race (despite randomization, more AAs were in the intervention). Paired sample $t$-tests evaluated changes in diet from baseline to post-test and baseline to follow-up by treatment group. All models were applied using modified intention-to-treat where participants were included if they provided data at baseline and post-test; the last observation was carried forward for those who completed post-testing but not follow-up (e.g. Farnier et al., 2005).

\section{Results}

Table 1 displays baseline participant characteristics by group. Sixty parents (69.0\%) completed post-testing; 31 (35.6\%) completed 6-month follow-up. Parents who completed post-testing had higher education and income $(p<0.05)$ than those who completed only baseline.

Repeated measures analyses (not shown) showed treatment*time interactions for child fiber and parent protein intake. Over time, control children consumed less fiber (grams/day) whereas intervention children had an increase in fiber intake from baseline to follow-up $(p<0.04)$. Intervention parents consumed a greater percentage of calories from protein $(p<0.01)$ and greater total protein (grams/day; $p<0.05)$ over time than controls. No other interactions were observed. Thus, overall, few treatment effects were found.

Table 2 presents parent and child dietary intake at each time point by group. In the intervention group, dietary improvements maintained from post-test to follow-up were found for parents' percent calories from protein, total carbohydrates (grams/day), total sugar (grams/day), and added sugar (grams/day); improvements in total calories (kilocalories/day) were found from baseline to post-test only. For control children; improvements maintained from post-test to follow-up were found for total energy (kilocalories/day) and total carbohydrates (grams/day); improvements in total and added sugar (grams/day) were found from baseline to follow-up only.

\section{Discussion}

Few differences in dietary intake between intervention and control groups were found at post-test or 6-month follow-up. However, a time effect was present, such that both groups demonstrated improvements in intake. Although unexpected, this finding is similar to Burrows et al. (2008), in which a parent group receiving minimal dietary education had 
comparable dietary changes to both a structured parent intervention group and a group targeting parents and children together.

Parents in NOURISH reported making dietary changes themselves, without concomitant changes in child intake. Control parents enrolled in the study seeking help for their children, but did not participate in a structured parent intervention or receive messages about the importance of role modeling healthy behaviors. Instead, information these parents received focused on the role of their child's diet in obesity. The finding that dietary improvements were generally found in intervention parents (who were targeted as agents of change) and control group children might reflect the interventions' different foci. Furthermore, greater attention to dietary intake may have resulted in reporting bias for intervention parents. Parental overweight, eating behaviors, and attitudes are related to childhood overweight (Birch and Fisher, 1998). Thus, the lack of parental change in controls and the positive parental changes in NOURISH, might indicate potential longer-term benefits for treatment group families. In addition, given the complex environments in which many children live (e.g., multiple caregivers/households), targeting additional caregivers may be needed to improve outcomes.

The control group included an in-person session about childhood obesity. Moderators noted that parents had numerous questions about nutrition that extended beyond the intended scope of this educational session. The group format may have provided social support for treatment-seeking parents and facilitated change. It is unknown if control parents sought out additional resources or implemented strategies to improve their children's eating. Although this session was much less intensive than NOURISH, it might have stimulated parents to make dietary changes for their children. In the currently ongoing R01 version of this intervention (NOURISH+), we have made changes to the intervention group to enhance the likelihood of positive dietary changes (e.g., individual sessions with a dietitian, grocery store tours, cooking classes).

Limitations include use of self-reported diet, and high, although comparable attrition (Skelton and Beech, 2010). Further, NOURISH was powered to detect the primary outcome of BMI percentile, thus we were underpowered to detect some dietary changes. Strengths are the examination of dietary intake in an innovative, parent-only pediatric obesity program, targeting AA families.

\section{Conclusions}

Despite few treatment effects, the positive dietary changes elicited in both treatment (parents) and control (children) groups suggest that, for parents who self-select into an obesity treatment program for their children, minimal intervention may be beneficial. However, more a more specific and intensive intervention is likely needed to meet dietary guidelines (USDA, 2011).

\section{Supplementary Material}

Refer to Web version on PubMed Central for supplementary material.

\section{Acknowledgments}

Sources of Funding

This study was supported by grants from the National Institutes of Health to SE Mazzeo [R03HD056050] and from the American Cancer Society to MK Bean [PFT-08-144-01-CPPB]. The conduct for this study was also supported by the National Institutes of Health for the VCU Clinical Research Center [UL1RR031990]. These funding sources had no involvement with the conduct of the research or preparation of the manuscript. 


\section{References}

Bandura, A. Social foundations of thought and action: a social cognitive theory. Englewood Cliffs, N.J.: Prentice-Hall; 1986.

Birch LL, Fisher JO. Development of Eating Behaviors Among Children and Adolescents. Pediatrics. 1998; 101:539-549. [PubMed: 12224660]

Burrows T, Warren JM, Baur LA, Collines CE. Impact of a child obesity intervention on dietary intake and behaviors. Int J Obesity. 2008; 32:1481-1488.

Centers for Disease Control and Prevention (CDC). [Accessed January 17, 2006] National Center for Health Statistics. Clinical Growth Charts. 2000. Available at: http://www.cdc.gov/growthcharts/.

Collins CE, Okely AD, Morgan PJ, Jones RA, Burrows TL, Cliff DP, Colyvas K, Warren JM, Steele JR, Baur LA. Parent diet modification, child activity, or both in obese children: an RCT. Pediatrics. 2011; 127:619-627. [PubMed: 21444600]

Collins CE, Warren J, Neve M, McCoy P, Stokes BJ. Measuring effectiveness of dietetic interventions in child obesity: a systematic review of randomized trials. Arch Pediatr Adolesc Med. 2006; 160:906-922. [PubMed: 16953014]

Farnier M, Freeman MW, Macdonell G, Perevozskaya I, Davies MJ, Mitchel YB, Gumbiner B. for the Ezetimibe Study Group. Efficacy and safety of the coadministration of ezetimibe with fenofibrate in patients with mixed hyperlipidaemia. Eur Heart J. 2005; 26:897-905. [PubMed: 15781429]

Feskanich D, Sielaff BH, Chong K, Buzzard IM. Computerized collection and analysis of dietary intake information. Computer Methods and Programs in Biomedicine. 1989; 30:47-57. [PubMed: 2582746]

Golan M, Kaufman V, Shahar DR. Childhood obesity treatment: targeting parents exclusively v. parents and children. Br J Nutr. 2006; 95:1008-1015. [PubMed: 16611394]

Janicke DM, Sallinen BJ, Perri MG, Lutes LD, Silverstein JH, Brumback B. Comparison of program costs for parent-only and family-based interventions for pediatric obesity in medically underserved rural settings. J Rural Health. 2009; 25:326-330. [PubMed: 19566621]

Kitzmann KM, Dalton WT 3rd, Stanley CM, Beech BM, Reeves TP, Buscemi J, Egli CJ, Gamble HL, Midgett EL. Lifestyle interventions for youth who are overweight: a meta-analytic review. Health Psychol. 2010; 29:91-101. [PubMed: 20063940]

Koplan JP, Liverman CT, Kraak VI. Preventing childhood obesity: health in the balance: executive summary. J Am Diet Assoc. 2005; 105:131-138. [PubMed: 15635359]

Mazzeo SE, Gow RW, Stern M, Gerke CK. Developing an intervention for parents of overweight children. Int J Child Adolesc Health. 2008; 1:355-363.

Mazzeo SE, Kelly NR, Stern M, Gow RW, Serdar K, Evans RK, Jones RM, Bulik CM. Nourishing our understanding of role modeling to improve support and health (NOURISH): Design and methods. Contemporary Clinical Trials. 2012

Ogden CL, Carroll MD, Kit BK, Flegal KM. Prevalence of obesity and trends in body mass index among US children and adolescents, 1999-2010. JAMA. 2012; 307:483-490. [PubMed: 22253364]

Samet, JM.; Alberg, AJ. Surrogate sources of dietary information. In: Willett, W., editor. Nutritional Epidemiology. New York: Oxford University Press; 1998. p. 157-173.

SAS/STAT® Software: Version 9. Cary, NC: SAS Institute Inc.; 2004.

Skelton JA, Beech BM. Attrition in paediatric weight management: a review of the literature and new directions. Obesity Reviews. 2010:e273-e281. [PubMed: 20880126]

United States Department of Agriculture (USDA). [Accessed February 25, 2012] Dietary Reference Intakes: Recommended Intakes for Individuals. 2011. Available at: http://fnic.nal.usda.gov/ nal_display/index.php? info_center=4\&tax_level=3\&tax_subject=256\&topic_id=1342\&level3_id=5140.

Whitaker RC, Wright JA, Pepe MS, Seidel KD, Dietz WH. Predicting obesity in young adulthood from childhood and parental obesity. N Engl J Med. 1997; 337:869-873. [PubMed: 9302300] 


\section{Table 1}

Baseline characteristics of NOURISH participants by group and results comparing groups on each variable

\begin{tabular}{|c|c|c|c|}
\hline Variable & $\begin{array}{c}\text { Intervention } \\
n_{\text {family }}=41 \\
n_{\text {parent }}=41 \\
n_{\text {child }}=44 \\
n(\%)\end{array}$ & $\begin{array}{c}\text { Control } \\
n_{\text {family }}=40 \\
n_{\text {parent }}=46 \\
n_{\text {child }}=44 \\
n(\%)\end{array}$ & $p$-value \\
\hline \multicolumn{4}{|l|}{ Female } \\
\hline Parent & $38(92.7)$ & $36(78.3)$ & 0.06 \\
\hline Child & $30(68.2)$ & $28(63.6)$ & \\
\hline \multicolumn{4}{|l|}{ Parent Race } \\
\hline African American & $30(73.2)$ & $23(50.0)$ & 0.03 \\
\hline Caucasian & $11(26.8)$ & $23(50.0)$ & \\
\hline \multicolumn{4}{|l|}{ Child Race } \\
\hline African American & $33(75.0)$ & $24(54.5)$ & 0.045 \\
\hline Caucasian & $11(25.0)$ & $20(45.4)$ & \\
\hline Married/Partnered & $18(45.0)$ & $22(47.8)$ & 0.80 \\
\hline Household Income $<\$ 35,000$ & $16(39.0)$ & $19(42.2)$ & 0.77 \\
\hline \multirow[t]{2}{*}{ Parent Education $\leq$ High school } & $7(17.5)$ & $10(23.3)$ & 0.52 \\
\hline & Mean (SD) & Mean (SD) & $\begin{array}{l}t \text {-value ( } p \text { - } \\
\text { value) }\end{array}$ \\
\hline Parent Age & $39.4(6.8)$ & $40.7(7.9)$ & $-0.77(0.45)$ \\
\hline Child Age & $8.7(1.5)$ & $8.5(1.5)$ & $0.36(0.72)$ \\
\hline Parent BMI ${ }^{a} \mathbf{k g} / \mathbf{m}^{2}$ & $34.6(9.2)$ & $33.4(8.6)$ & $0.64(0.53)$ \\
\hline Child BMI ${ }^{a}$ Percentile & $98.2(2.8)$ & $97.8(2.6)$ & $0.68(0.50)$ \\
\hline
\end{tabular}




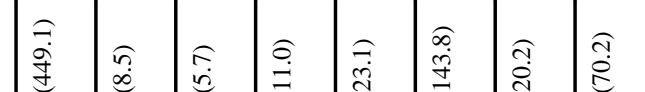

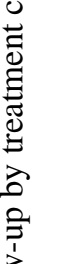

ప

苛苞

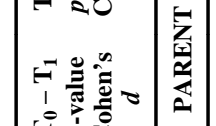

言

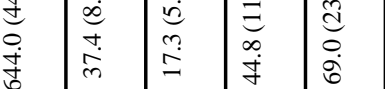

a

है

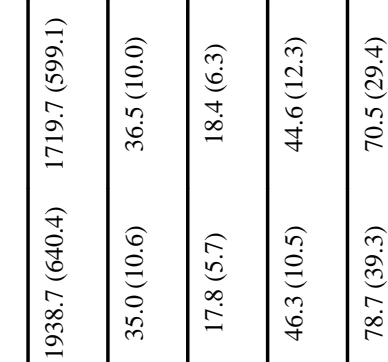

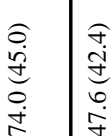

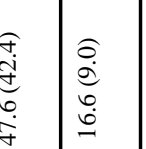

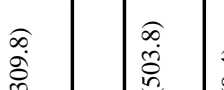

总

离高

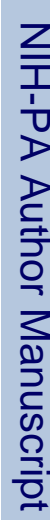

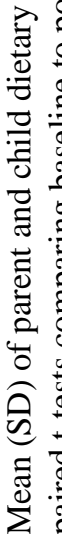

홍

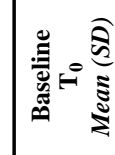

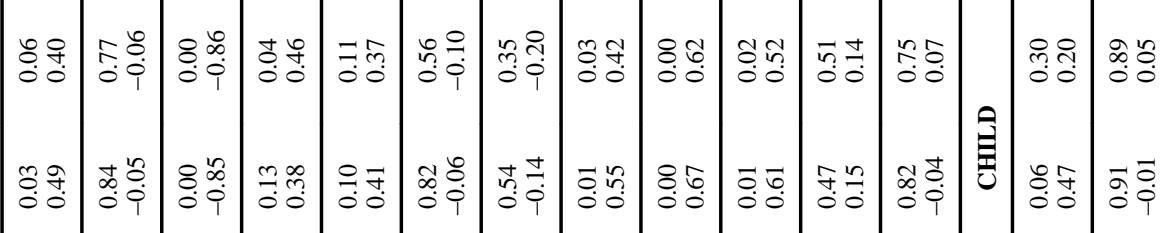

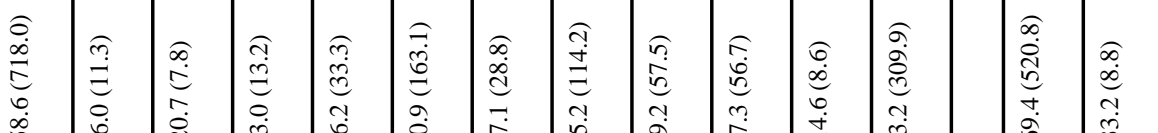

3 प

ลิ

这

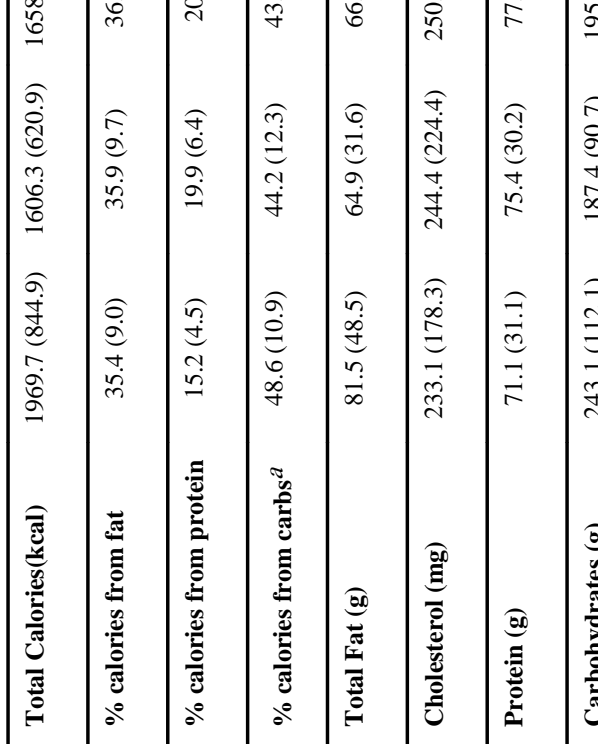

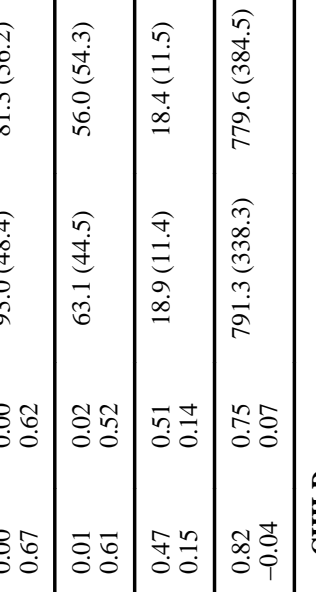

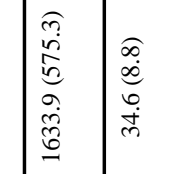

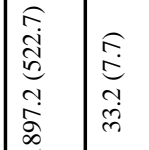




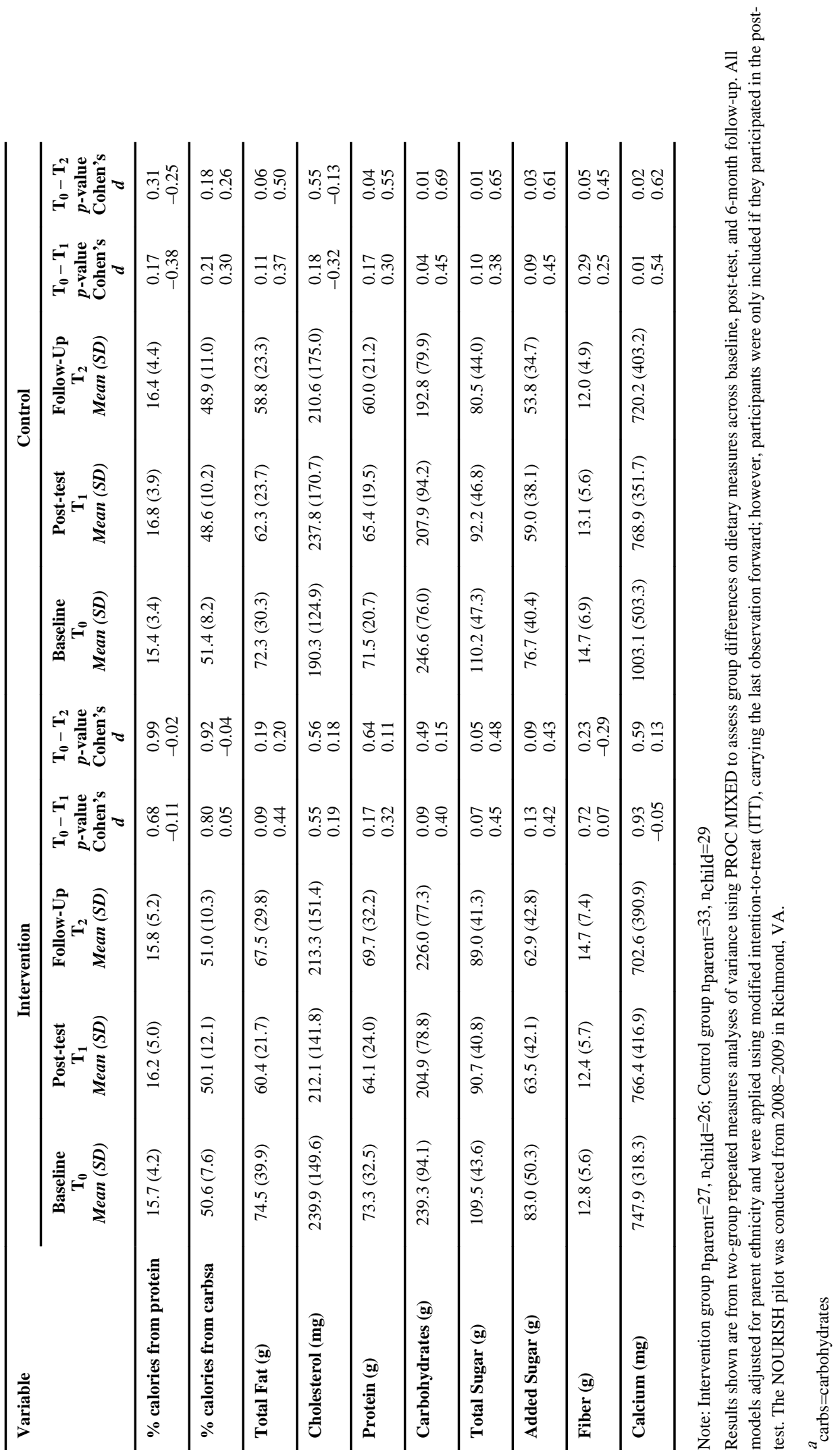

